\title{
Dropouts Thoughts on Whether Having a Mentor Would Have Helped Them Remain in School
}

\author{
Raqota Berger \\ College of Social and Behavioral Sciences, California State University, Northridge, USA \\ Email: rberger@vcccd.edu
}

How to cite this paper: Berger, R. (2019) Dropouts Thoughts on Whether Having a Mentor Would Have Helped Them Remain in School. Open Access Library Journal, 6: e5718.

https://doi.org/10.4236/oalib.1105718

Received: August 20, 2019

Accepted: September 7, 2019

Published: September 10, 2019

Copyright $\odot 2019$ by author(s) and Open Access Library Inc.

This work is licensed under the Creative Commons Attribution International License (CC BY 4.0).

http://creativecommons.org/licenses/by/4.0/

\section{(c) (i) Open Access}

\begin{abstract}
Millions of high school and college students drop out each and every year. For many of these individuals there are resultant problems associated with dropping out, such as being unemployed and living in poverty. Those that graduate from school, especially from college, realize many benefits over the life course. This study looked at the thoughts and attitudes of school dropouts regarding whether or not having a school-based mentor would have helped them to stay enrolled in their respective programs. This study collected information from 381 school dropouts. The findings from this project suggest that having a mentor would be a valuable resource for those students that are at risk of leaving their programs before they graduate. The general findings revealed that the majority of respondents felt that having a school professional working closely with them would have helped them to remain in their classes. Mentoring programs help at-risk students to feel more engaged, less isolated, and more committed to their studies. Mentoring programs aid in improving overall academic standing and they also serve to decrease dropout rates. These findings should be of use to professionals working in any educational setting, such as teachers, program directors, and counselors.
\end{abstract}

\section{Subject Areas}

Education, Sociology

\section{Keywords}

Mentoring Students, Dropping Out, Connectedness, Engagement, Isolation

\section{Introduction}

Millions of students drop out of high school and college every year across the 
United States. It is estimated that around 7000 students drop out of high school each and every day in America. It is also estimated that over 2 million college students will drop out of their respective programs each academic year [1] [2] [3]. There are many social, economic, and interpersonal costs associated with dropping out. Those that drop out of school at the high school or college levels are more likely to be unemployed, to live in poverty, to rely on government welfare programs, and to be unsatisfied with their jobs. Those that drop out of school are also more likely to have every type of major health condition (e.g., heart disease, diabetes), to be suffering from mental health conditions (e.g., depression), and to be living in less than optimal social and physical environments [4] [5]. The point here is that dropping out school often comes with a range of lifelong consequences that many do not take into consideration when they make the decision to leave school before graduating.

There are many different reasons that students drop out of school, such as the need to make money, disinterest in classes, pregnancy, family problems, etc. [6]. Many will leave due to unforeseen circumstances that left them little choice (e.g., family crisis), while others leave due to short-term thinking, lack of patience, and immaturity. Still yet, others leave school because they simply do not feel integrated or engaged in their schools or programs. Many will drop out of high school and college each year because they do have any real career plans and feel like they are drifting through their courses. This is where school-based mentoring programs can come into play and help these faltering students become more invested and connected with their classes and programs. Having a school-based mentor has been shown to significantly reduce dropout rates and improve overall academic performance [7] [8].

This project has set out to further investigate the role that mentoring could play in reducing school dropout rates. A central purpose of the work was to gain deeper insight into the thoughts and attitudes of those that have dropped out of school at some point in their lives. The goal was to investigate the perceived value of having caring mentors and other school-based professionals working closely with students that are at risk of dropping out. The findings of the undertaking should be of use to professionals working throughout educational settings, such as principals, teachers, professors, chairs, administrators, program directors, counselors, and so forth.

\section{Overview of the Literature}

The United States has the highest dropout rates in the world. Over 13,000 American students drop out of high school and college every single day [9] [10]. Those that drop out of school earn significantly less in income across their working lives than those that graduate from college. On average, college graduates earn around $\$ 1$ million dollars more than those that only graduate from high school [11]. Dropping out of school does not just impact the lives of those that decide to leave their programs. School dropouts cost American taxpayers 
hundreds of billions of dollars each year in government programs and financial assistance. College dropouts also owe more than $\$ 500$ billion in student loans, which they are far more likely to default on than those that graduate [12] [13] [14]. Those that drop out of school are also more likely to be chronically unemployed, to live in poverty, to be incarcerated, and to die at a younger age than those that have earned college degrees [15] [16] [17]. Earning a college degree is associated with higher levels life satisfaction, better mental and physical health, and longevity.

There are many reasons why people make the decision to drop out of school. One of the top reasons that students drop out of school is due to the need to make money. The need to work full-time, the high cost of tuition, lack of preparation, lack of motivation, lack of direction, pregnancy, and family problems are other major reasons why people drop out of school [6] [18] [19]. Students also drop out of school because they often feel disconnected and uncertain. One of the main psychological reasons that students drop out is because they often feel isolated from other students and from their teachers. Helping students to feel more connected and engaged has been shown to be an effective way to improve motivation, academic performance, and to reduce attrition rates [6] [14]. The current dropout crisis is a complex problem that goes far beyond the mere individual and has risen to the level of becoming a national epidemic [2] [9].

There are many different things that schools and colleges can do to help keep their students enrolled. Lowering dropout rates (or keeping dropout rates low) is something that all educational institutions are concerned about. In higher education, the highest dropout rates occur at community colleges. At this level, around 1 out of every 3 students that enter community college will drop out within the first few years [4] [20]. Only around 33\% of all college students will wind up earning a college degree, and the majority of these dropouts will leave owing an average of $\$ 40$ thousand dollars in student loan debt [21] [22] [23]. One of the best ways to keep students in their classes is to get them more engaged and connected. Helping students build a clear path to educational success has been shown to be one of the most effective ways to improve retention rates and to improve overall academic performance [6] [7]. There are many market and nonmarket benefits to graduating from college, so all educational leaders and educators must work hard to keep students enrolled and on a path to academic success [5].

Having effective and integrated mentoring programs at high schools and colleges has been shown to significantly improve academic standing and increase retention rates [7] [24]. Being connected to a mentor increases student motivation, reduces feelings of isolation, helps to improve classroom skills, and helps students to feel more focused [15] [24]. Mentoring programs have been particularly effective at reducing dropout rates among at-risk students (e.g., low income students, first-generation students, underrepresented students). At-risk students that are involved in mentoring programs are significantly less likely to drop out than their counterparts that are not involved in mentoring programs [7] [25]. 
Mentoring programs are relatively inexpensive to operate and they can be specially designed to serve any type of at-risk student population. Having an involved mentor has been widely shown to make students feel more confident and more motivated to succeed in their classes. Substantial empirical evidence has widely shown that mentoring programs are highly effective at helping students to improve their overall grade point averages, to increase commitment to their programs, and to significantly decrease the chances that they drop out [7] [15] [24]. The current project has been designed to take a close look at the issue of dropping out of school and what could potentially be done to help improve this ongoing cultural and education problem. Professionals working in any type of educational setting should know as much as possible about this particular topic.

\section{Project Method}

\subsection{Design of Project}

Data for this study were collected via a quantitative questionnaire. The questionnaire was designed to collect fixed-choice responses to allow for subsequent statistical analyses. Respondents were asked to provide discrete responses to closed-ended questions (e.g., Yes/No) asking about their thoughts on dropping out of school and whether having a mentor would have helped them to remain in their classes. There were also questions asked that provided more continuous data, which allowed for a broader range of analyses (e.g., age when they dropped out of school). The fundamental purpose of the study was to capture respondents' thoughts and attitudes about dropping out of school and whether or not having someone at the school working closely with them would have helped them to remain in their programs. This was an independent study and no external funding was provided. The study was designed to gather certain demographic information so that group contrasts could be made in regard to attitudes and beliefs about dropping out and school mentorship. Specific demographic variables of interest involved age, ethnicity, gender, and social class. Data were collected on all four levels of measurement. Analyses were run at both the descriptive and inferential levels to help foster a more perspicacious understanding of the topic at hand. The questionnaire was able to be completed in around two to three minutes. No compensation was provided for participation in the study. To ensure proper ethics with this particular population and topic of focus, all respondents were informed about the nature of the study and what they would be asked about. This helped to ensure that all respondents were comfortable with filling out the survey. No deception was used in the study and consent as given by the respondent's willingness to fill out the questionnaire. All questionnaires included in the final sample and analysis were deemed to have been filled out in an honest and valid manner.

\subsection{Study Participants}

The final valid sample size for this study was 381 . This sample size meets the 
sample requirements for the population and analyses of interest at the $95 \%$ confidence interval (power $=0.80, \mathrm{ME}=5 \%$ ). All participants in the study have dropped out of school at some point in their lives. The majority of the study participants were living in California at the time that they filled out the questionnaire. Some participants were residing in other states and were surveyed through phone interviews. Participants for this study were selected through a purposive sampling technique. Study participants were asked if they could refer the researcher and research assistants to additional school dropouts. This method allowed for the study to procure a larger final sample size. All respondents needed to be at least 18 years of age to participate in the study. Participants were allowed to ask clarifying questions while they were filling out the instrument so that their responses were valid and represented their true thoughts and attitudes about the topic. Table 1 highlights the demographics of the final sample. As can be seen from the table, the majority of the sample was made up of Hispanic respondents. Hispanics make up the majority in Los Angeles county, so this is in proportion with the larger regional demographics. Two participants $(0.5 \%)$ did not respond to this question. Men made up the majority of respondents ( $n=201,52.8 \%$ ). This is proportionate with dropout rates across America, as males make up the highest percentage of school dropouts at both the high school and college levels. There were 175 women in the final sample (45.9\%). Two respondents $(0.5 \%)$ identified themselves as belonging to a different gender category, while 3 respondents $(0.8 \%)$ did not answer this question. The largest percentage of respondents identified with being members of the working class $(57.5 \%)$, followed by middle class (29.5\%), lower class (11.4\%), and upper class (1.6\%).

\subsection{Examination of the Data}

The final data collected for this study were examined via the statistical software program SPSS 24. Descriptive and inferential statistics were analyzed across both the categorical and continuous variables. Measures of central tendency were produced across the relevant variables, as were certain measures of variability. Multiple symmetric measures were taken across the discrete and continuous variables (e.g., Spearman's R, Cramer's V, Contingency Coefficient). Multiple crosstabulations were conducted across the discrete variables to get a better sense of group differences. Chi-Square tests of significance were also executed to help allow for inferential interpretations of the findings regarding group differences. All inferential tests of significance were set at the standard probability of 0.05 . Any correlational measures or group differences that exceeded the $0.05 \mathrm{lev}$ el of significance were regarded as statistically insignificant and were analyzed as such. Only results that have met the set probabilistic threshold were examined further and elucidated on in this final report. All tests of inference were two-tailed for the purposes of this study. Due to small sample numbers across certain categories (e.g., Native Americans), it was necessary to eliminate certain groups from specific tests and analyses. 
Table 1. Demographic characteristics of sample.

\begin{tabular}{ccc}
\hline Ethnicity & Frequency & Percentage \\
\hline Hispanic & 212 & 55.6 \\
White & 100 & 26.2 \\
Black & 24 & 6.3 \\
Asian & 20 & 5.2 \\
Middle Eastern & 12 & 3.1 \\
Multiracial & 10 & 2.6 \\
Native American & 1 & 0.3 \\
\hline
\end{tabular}

\section{Project Results}

When asked if having a mentor would have helped them to remain in school the majority of respondents stated that it would have helped (55.1\%). Asian (80\%) and Multiracial (70\%) respondents were the most likely to believed that having a mentor would have helped them to remain in school. This was followed by Hispanic (59.9\%), White (45\%), Black (37.5\%), and Middle Eastern (33.3\%). The single Native American respondent stated that having a mentor would have helped. When asked if having someone at the school working closely with them (e.g., teacher or counselor) would have helped them to remain in their classes the majority stated that it would have (65.6\%). Again, it can be seen that Asian respondents $(85 \%)$ were still the most likely to believe that it would have helped them, followed by Hispanic (72.2\%), Multiracial (60\%), Black (54.2\%), White (54\%), and Middle Eastern (41.7\%). The single Native American participant also stated that this would have helped. A chi-square test comparing ethnic group differences produced significant results, $\mathrm{X}^{2}(7)=18.67, \mathrm{p}=0.009$. Nominal by nominal symmetric measures also produced significant findings $(\mathrm{V}=0.009, \mathrm{C}=$ 0.009). Multiple group differences were detected in regard to whether or not having a school professional working closely with the respondents would have helped them to remain in school. As an example, Asian and Hispanic respondents had significantly different views on this than Middle Eastern respondents. The same can be said about the multiracial respondents and the Middle Eastern respondents. There were no significant differences between Black and White respondents in this regard.

When asked if having a mentor would have help respondents to remain in school, the majority of both women (58.9\%) and men (51.2\%) stated that it would have helped. Of the two respondents that identified as "other," one believed that a mentor would have helped, while the other did not. A chi-square analysis did not reveal differences between women and men, $\mathrm{X}^{2}(1)=2.37, \mathrm{p}>$ 0.05 . When asked if having a school professional working closely with them (e.g., teacher, counselor) would have helped them to remain in school, most of the women $(70.3 \%)$ stated that it would have helped. Most of the men $(60.7 \%)$ also felt this way. Both of the respondents that identified as "other" believed that having someone working with them would have helped them to stay in their classes. Inferential statistics could not properly be performed on the "other" cat- 
egory due to small sample size. There were no statistically significant differences detected between men and women in regard to their beliefs about having a mentor, teacher, counselor or staff working closely with them and their decision to drop out of school. The majority of both men and women generally believed that having someone at the institution working with them would have impacted their decision to leave school.

In regard to social class differences, only working-class respondents had a majority that felt that having a mentor would have helped them to remain in school (60.8\%). This is significant seeing this particular group made up $57.5 \%$ of the total sample. Of the middle-class respondents $48.6 \%$ felt that it would have helped, while $45.2 \%$ of the lower-class respondents felt this way. The upper-class sample was too small for statistical confidence, but $33.3 \%$ stated that a mentor would have helped. When asked about having a school-based professional working closely with them (e.g., teacher, counselor) and remaining in school, all social class groups leaned in the positive direction. Around 7 out of 10 working-class respondents $(70.8 \%)$ felt that having a professional working with them could have changed their decision to leave school before graduating. The remainder of the classes broke down as, middle-class (59.6\%), lower-class (54.8\%), and upper-class $(50.1 \%)$. A chi-square analysis detected significant differences between social class and attitudes about having a mentor and remaining in school, $\mathrm{X}^{2}(2)=6.39, \mathrm{p}<0.05$. Those from the working-class were significantly more likely than those from the lower-class and middle-class to feel this way. Upper-class respondents were removed from the analysis due to small sample size. Based on these findings it would appear as though having someone working closely with them would have helped the majority of students, regardless of social class background, to have remained in school and complete their respective programs.

\section{Discussion of the Study}

Graduating from high school is an important step in aging and development. On average, high school graduates earn more money and have lower rates of unemployment that high school dropouts. Graduating from college is even more strongly associated with stable employment and higher life satisfaction. College graduates earn significantly more money across their professional lives, they tend to live longer, they live in safer neighborhoods, and they even tend to be in better mental and physical heath [5] [10] [17]. There are many reasons to remain in high school and college. To put it simply, those that graduate tend to have better lives overall. This is not to say that everyone needs to earn an undergraduate degree, there are many other viable options. It could be argued that learning an applied trade may be a less expensive and more practical route to take. There is a good argument to be made here. The problem really comes into play when people drop out of school and they do not have any real plan for what they want to do. Dropouts are also likely to owe a significant amount of money in school loans, which many cannot pay and ultimately default on [2] [22]. With 
this stated, the reality is that earning a higher-level degree is the single best way to ensure financial stability across the life course. There are other factors that play into this of course, but this the most significant single factor.

This study has brought forth firsthand data to help highlight the thoughts and beliefs of those that have dropped out of school at any level (high school, community college, or university) and whether having a mentor or other school-based professional working with them would have helped them to remain in their classes. Based on the collected data it would appear that the clear majority of the respondents felt that it would have help (65.6\%). There are instances where nothing will prevent someone from dropping out (e.g., family crisis, medical emergency). Having a mentor would not make a difference in these kinds of particular instances; although it may give them more motivation to return after things in their lives improve. With this said, having a mentor or other school-based professional working closely with most students will help to make them feel more engaged, connected, and committed to their coursework [15] [24]. This is particularly true for students that are deemed to be a trisk of dropping out.

This project has illuminated the thoughts and beliefs of school dropouts in regard to whether or not having someone supporting them would have helped them to stay enrolled and to ultimately be successful in school. The data collected for this study reveals that most women and men feel that it would have. In regard to ethnicity, the data also shows that those from almost all ethnic groups also believe that having a mentor or school-professional working closely with them would help them to remain in their programs. This was especially evident for Asian and Hispanic respondents. These two groups leaned heavily toward the favorability of having mentors. Black, White, and Multiracial respondents also leaned toward the positive side of this, but it was not as pronounced as it was with Asian and Hispanic dropouts. Only Middle Eastern respondents leaned in the direction that it would not have made any difference in their decision to leave school before graduating. In the final analysis it would appear that having a school-based mentor is something that most at-risk students would welcome. School-based mentoring programs have been widely shown to be quite effective at lowering dropout rates among at-risk students, increasing engagement, and improving overall academic standing [8] [25]. It would be in the best interest of schools at all levels to implement certain kinds of programs whereby at-risk students can have a place to go and where they can connect with caring professionals that can help guide them through the entire academic process. Having mentors working closely with students is one of the best ways to ensure that they remain in their programs and ultimately earn those culturally coveted academic credentials.

\section{Limitations and Future Research}

This study collected quantitative data to assist with larger group comparisons and statistical analyses. 
With this being the case, it was not possible to probe deeper into the motivations and reasons that students dropped out of school. It was also not possible to fully investigate whether or not having a school-based mentor would have helped them to remain in school. To better make sense of the rationale and behaviors of the respondents it would be necessary to conduct further studies that could probe deeper into these matters. Further studies could spend more time with individuals that have dropped out of school to gain ancillary insight into their choices and motivations. This may be accomplished via interviews and focus group designs. This study is also limited in the sense that some of the groups included had very small samples sizes (e.g., Native Americans, upper-class respondents). Additional studies could collect more information from these particular group members to gain further insight and understanding into their decisions and actions. Additional research could also collect data from a broader range of people from around the nation (e.g., South, Mid-West). Advancing this topic in these ways would aid in building a more complete understanding on the topic of dropping out of school and on school-based mentoring.

\section{Conclusion}

This study has brought forth further evidence for the value and need of academic mentors. There are millions of at-risk students across the nation. Millions of these students will drop out of high school and college each and every year. There are many costs of not obtaining academic credentials, and concerned school-based professionals need to do all they can to help ensure that these students get the attention and guidance that they need. Working closely with school-based mentors has been shown to decrease dropout rates and to improve overall academic performance. This project has shown that the majority of school dropouts do believe that having a mentor working with them would have helped them to remain in school. There are many social consequences of having a society with massive numbers of dropouts. It is in the best interest of the nation to do as much as necessary to make sure that at-risk students remain in their classes and ultimately earn those highly rewarded academic honors. Lowering school dropout rates would assuredly help to significantly reduce many of the nation's ongoing problems with unemployment, poverty, homelessness, and crime. Helping the nation's at-risk students to earn higher-level degrees would have a direct impact on improving the lives of millions of American families.

\section{Conflicts of Interest}

The author declares no conflicts of interest regarding the publication of this paper.

\section{References}

[1] Hess, F.M. and Christensen, C. (2018) Dropout Crisis: Rewarding Colleges for 
Cooking the Books Won't Solve It. National Review.

https://www.nationalreview.com/2018/08/college-dropout-crisis-performance-base d-funding

[2] Leonhardt, D. (2018) A New Dropout Crisis. The New York Times. https://www.nytimes.com/interactive/2019/05/23/opinion/sunday/college-graduatio $\underline{\text { n-rates-ranking.html }}$

[3] National Student Clearinghouse (2014) Signature Report: Some College, No Degree-A National View of Students with Some College Enrollment But No Completion. National Student Clearinghouse Research Center, Herndon.

[4] Dickler, J. (2017) Student Loan Balances Jump Nearly 150 Percent in a Decade. https://www.cnbc.com/2017/08/29/student-loan-balances-jump-nearly-150-percent -in-a-decade.html

[5] Heckman, J.J., Humphries, J. and Veramendi, G. (2018) The Nonmarket Benefits of Education and Ability. Journal of Human Capital, 12, 282-304. https://doi.org/10.1086/697535

[6] Berger, R. (2019) The Problem of Dropping out and Why Students Leave School before Graduating. International Journal of Psychological Research, 2, 1-9. https://doi.org/10.28933/ijprr-2019-01-1005

[7] Irby, B.J. (2011) Mentoring and Tutoring in Schools and Universities. Mentoring and Tutoring: Partnership in Learning, 19, 121-124.

https://doi.org/10.1080/13611267.2011.564346

[8] Williams, A., Northcote, M.T., Kilgour, P.W. and Stewart, B. (2018) The Virtual Mentor Program: An Initiative to Support First-Year Students and Students at Risk. The Journal of Adventist Education, 80, 22-29.

[9] Barshay, J. (2017) 3.9 Million Students Dropped out of College with Debt in 2015 and 2016. U.S. News \& World Report.

https://www.usnews.com/news/data-mine/articles/2017-11-07/federal-data-show-3 9-million-students-dropped-out-of-college-with-debt-in-2015-and-2016

[10] Lynch, M. (2016) High School Dropout Rate: Causes and Costs. The Edvocate. https://www.theedadvocate.org/high-school-dropout-rate-causes-and-costs

[11] Ballantine, J.H. and Hammack, F.M. (2017) The Sociology of Education: A Systematic Analysis. 8th Edition, Routledge, New York. https://doi.org/10.4324/9781315299914

[12] American Public Health Association (2018) The Dropout Crisis: A Public Health Problem and the Role of School-Based Health Care. Author, Washington DC.

[13] Chen, G. (2018) The High Cost of Community College Dropouts. Community College Review.

https://www.communitycollegereview.com/blog/the-high-cost-of-community-colle ge-dropouts

[14] Hess, A. (2017) Bill Gates: US College Dropout Rates Are "Tragic". CNBC Make It. https://www.cnbc.com/2017/10/10/bill-gates-us-college-dropout-rates-are-tragic.ht $\underline{\mathrm{ml}}$

[15] Capstick, K.M., Harrell-Williams, L.M., Cockrum, C.D. and West, S.L. (2019) Exploring the Effectiveness of Academic Coaching for Academically At-Risk College Students. Innovative Higher Education, 44, 219-231. https://doi.org/10.1007/s10755-019-9459-1

[16] Peguero, A.A., Ovink, S.M. and Li, Y.L. (2016) Social Bonding to School and Educational Inequality: Race/Ethnicity, Dropping Out, and the Significance of Place. So- 
ciological Perspectives, 59, 317-344. https://doi.org/10.1177/0731121415586479

[17] Quadagno, J. (2018) Aging and the Life Course: An Introduction to Social Gerontology. 7th Edition, McGraw-Hill, New York.

[18] Hess, F. (2018) The College Dropout Problem. Forbes. https://www.forbes.com/sites/frederickhess/2018/06/06/the-college-dropout-problem

[19] Weissmann, J. (2012) Why Do So Many Americans Drop Out of College? How America's Higher Education System Became One Big Dropout Factory. The Atlantic.

https://www.theatlantic.com/business/archive/2012/03/why-do-so-many-American s-drop-out-of-college/255226/

[20] National Center for Education Statistics (2019) Enrollment and Employees in Postsecondary Institutions. https://www.nces.ed.gov/pubsearch/pubsinfo.asp

[21] Carlson, S. (2016) When \$300 Dollars Would Keep a Student from Dropping Out. Chronicle of Higher Education, 62, 1-5.

[22] Friedman, Z. (2018) Student Loan Debt Statistics in 2018: A \$1.5 Trillion Crisis. https://www.forbes.com/sites/zackfriedman/2018/06/13/student-loan-debt-statistics $\underline{-2018}$

[23] Sagenmuller, I. (2019) Student Retention: 8 Reasons People Drop Out of Higher Education. U-Planner.

https://www.u-planner.com/en-us/blog/student-retention-8-reasons-people-drop-o ut-of-higher-education

[24] Moschetti, R.V., Plunkett, S.W., Efrat, R. and Yomtov, D. (2018) Peer Mentoring as Social Capital for Latina/o College Students at a Hispanic-Serving Institution. Journal of Hispanic Higher Education, 17, 375-392.

https://doi.org/10.1177/1538192717702949

[25] Larose, S., Chaloux, N., Monaghan, D. and Tarabulsy, G.M. (2010) Working Alliance as a Moderator of the Impact of Mentoring Relationships among Academically At-Risk Students. Journal of Applied Social Psychology, 40, 2656-2686. https://doi.org/10.1111/j.1559-1816.2010.00675.x 